\title{
Monipay: Food Consumption and Money Outlay Monitoring System
}

\author{
Warren Earl P. Cruz, Ethan Gabriel C. Jose, Reynaldo V. Magallanes, \\ Alexandria Gabrielle V. Muyot , John Benedict C. Legaspi ${ }^{+}$, and Heintjie N. Vicente \\ FEU Institute of Technology, Philippines
}

\begin{abstract}
Supervision regarding the wellness and security of the students of NBCA International School is insufficient. As for short break times and only one concessionaire, negligence in the school's canteen is prominent. To administer and enrich the wellbeing of each student, MoniPay intends to monitor the consumption and expenditures of food purchased using NFC or Near-Field Communication cards where parents are notified of the student's procuring activities. Reports of student's daily and weekly expenditures are accessible in the parent application. This study emphasizes the need for the system to fulfill what is lacking in administering the wellness of the students in the school. This study is quantitative research wherein data is collected by way of surveys answered by respondents chosen through a purposive sampling technique to improve the system. The results and objectives have been met in line with the gathered information from research, interview, and surveys.
\end{abstract}

Keywords: NFC; Near-Field Communication; MoniPay; Wellness; Reports; Mobile Application

\section{Introduction}

School breaks particularly recess, and lunch are very significant for students. However, these break times have allotted time including walking to the canteen, standing in line, choosing their meal, and paying for their meal cutting short the time to eat their meals. The first obstacle students face in break times is to stand in line for their meals, consuming most of their break time. Lines stack long enough to leave students a few minutes to eat. A short time for meals may cause rushed eating, resulting in detrimental effects such as obesity [1].

MoniPay aims to aid common matters that occur in schools' canteens by providing a cashless payment system with features that could be beneficial for students, parents, and concessionaires. The system will attend to the specific requirements to make it suitable for what each user group is dealing with accordingly.

NBCA International School started catering quality education to local and foreign students in 2006. The Christian school currently operates in full swing for its pre-school, primary, junior and high school levels. The school is committed to guaranteeing that the students have the ability to learn in a safe, healthy, and comfortable environment. With that, the school is looking for ways to ensure the welfare of each student by also giving attention to their health and safety. With short break times and one concessionaire attending to the given number of enrolees, there is neglect in supervision concerning the wellness and security of the students. Therefore, MoniPay will serve its purpose by administering and enriching the wellbeing of each student.

With the help of a cashless payment system, MoniPay, the concessionaires will be able to hasten their process of payment and recording sales. This can help concessionaires minimize the long queues, thus allowing students to have more of their break time and promote their security and wellness.

Figure 1 shows the function of each user group with the system. The student is provided with the expense limit imposed and the balance loaded by the respective parent whilst allowing payment for transactions inside the school. The admin may add, remove, edit, or delete student info who are eligible to use the system. Also, the admin is responsible for disabling transactions and user accounts maintenance. Transaction history and all reports conducted would reflect the admin. Turning to the parent, food restriction

John Benedict C. Legaspi. Tel.: +63 9273965080.

E-mail address: jclegaspi@feutech.edu.ph 
following their child's dietary needs can be implemented. Parents can load balance by choosing from the mobile payment platforms available through the system. Also, parents can set the expense limit and disable transactions when necessary. Furthermore, the system will reflect periodical expenditure reports, repeat purchase reports, and transaction history of the students to the parents. Similarly, reports made by the concessionaire regarding its transaction history will be issued to both the parent and the admin. The concessionaire provides available products with its key ingredients. Moreover, the system will issue its sales report and transaction history as well as the restricted food set by the parent of the student.

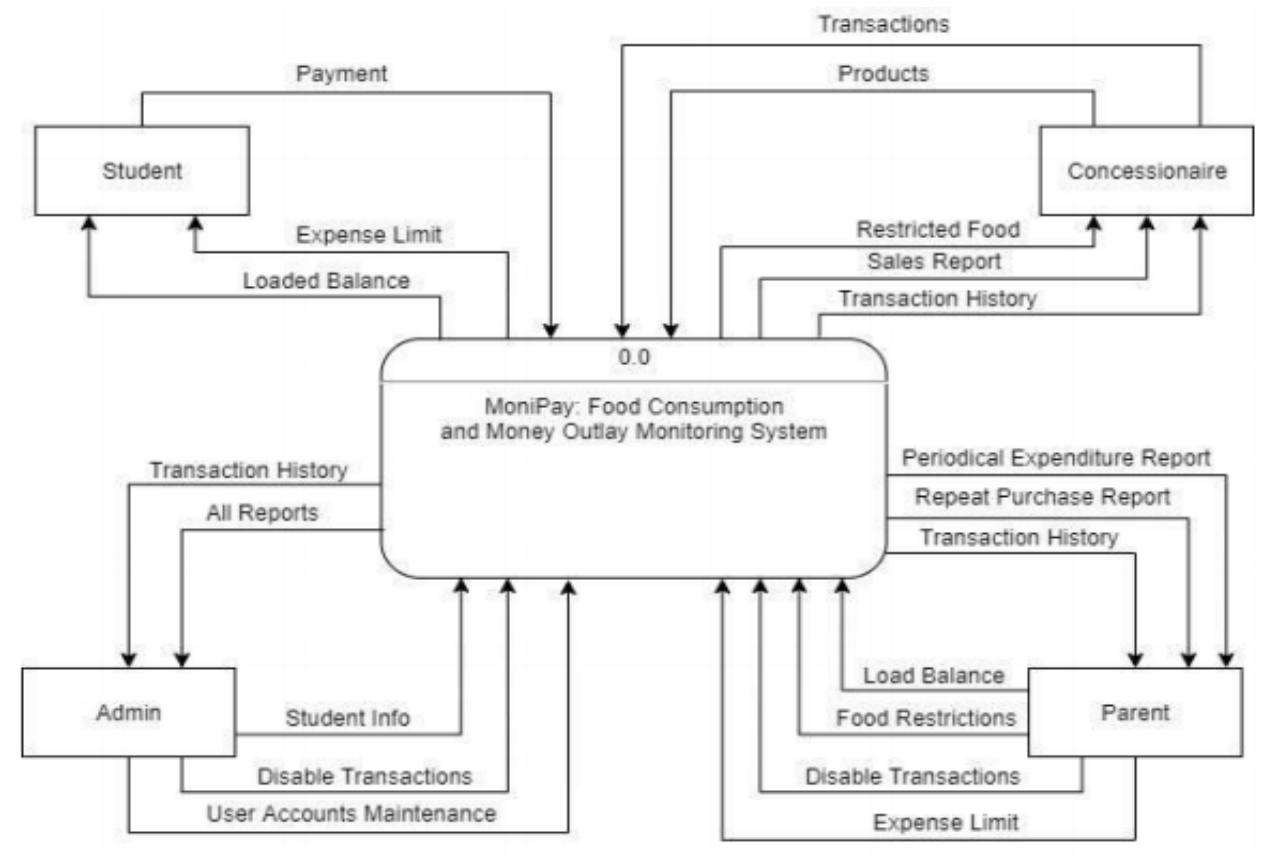

Fig. 1: Context Flow Diagram of the System

The general objective of the project is to develop a system with web and mobile applications that monitors the consumption and expenditures of food for students of NBCA International School.

\section{Specific Objectives}

- To create a reports module producing graphs in regard to the transactions of and with the students for parents and concessionaires.

- To create a top-up module for parents to load money for their child's card

- To create a restriction module to allow parents to identify their child's food allergies or any food restrictions

- To create a management module for parents to set their child's spending limit, disable further transaction in case of a lost card, and edit student profile

- To create a management module for the admin to add, remove, and edit student profiles

- To create a Point-of-Sale system for concessionaires

- To integrate the use of NFC cards as a medium for payment

- To integrate an API that will facilitate payment workflow

- To design a perspicuous user interface

- To evaluate the system with FURPS model

The study will focus on developing a smart card payment system exclusive to transactions with vendors inside a school. It will have a website and mobile application that will accommodate the users to a faster and monitored transaction inside the school with analytics for routine purchases or purchase behavior.

This study will be beneficial to students, parents, and concessionaires. Firstly, students will be able to purchase from concessionaires inside the school through their school ID. Secondly, Parents will be able to track and monitor every purchase done by their child as it is logged with timestamps into the parents' portal. Lastly, concessionaires will be able to benefit from a POS system that can audit sales and generate summary reports reducing manual operation. 


\section{Literature}

As digital payments progress, some schools are gradually incorporating this technology in their operations. For instance, Saint Louis University (SLU), a private Catholic university in Baguio, Philippines, has deployed an extensive radio frequency identification solution that encompasses student and employee access, asset tracking and library management, all on a single platform. The solution was provided by Image Innovations Services (IIS), using Portable Technology Solutions (PTS)'s Clear Stream RFID middleware. The deployment started in the library, but the technology is now tracking individuals' ID badges, as well as asset tags at all campus and parking-lot entrances [2].

The old-fashioned piggy banks in a cashless society will transform into virtual ones. Through the digital pocket money app, kids will learn to save money virtually because they are still too young to get the traditional banks. Other parents stating when kids have the cash, they want to spend it quickly. But through apps, it will let them check their balance which makes them think about saving rather than spend it unwisely. In the U.S. Merchants are increasingly turning cashless which makes it harder for children without bank cards. But with these money apps, parents can load money from their bank unto their own account, set weekly allowance and limits their children for spending it in some online shopping [3].

As for the trend of e-money in the Philippines, an abundance of Filipinos is not using banks, with 43.2\% having savings account whereas only $32.7 \%$ of it have an actual bank account. This led the government to institute e-finance in the country, spearheaded by GCash and Smart Money, to reach unbanked, unserved, or underserved Filipinos with proper financial products and services. However, despite the increase in active emoney accounts, $10.1 \%$ Filipinos do not trust the service provider and lack the knowledge on how to transact with e-money. Even so, a greater joint effort among banks and government agencies will be needed in order to expand the usage of e-finance in the country [4].

Kadir et al. [5] concluded in their study that NFC technology in campus canteen pose an effective transaction and security for the students. As NFC payment is cashless, this also solves the issue of long queues in canteens due to the slow traditional process of payment. The system uses smartphones with NFC technology for transactions, but credit must first be loaded into it. Students no longer need to worry about the risk of bringing cash to school to buy food and drinks in school.

\section{Methodology}

A quantitative approach was used in the research and in order to collect data to improve the system a survey was conducted. A sampling technique of purposive sampling was also used and to save time and cost, a researcher's judgement was employed in selecting the respondents to participate.

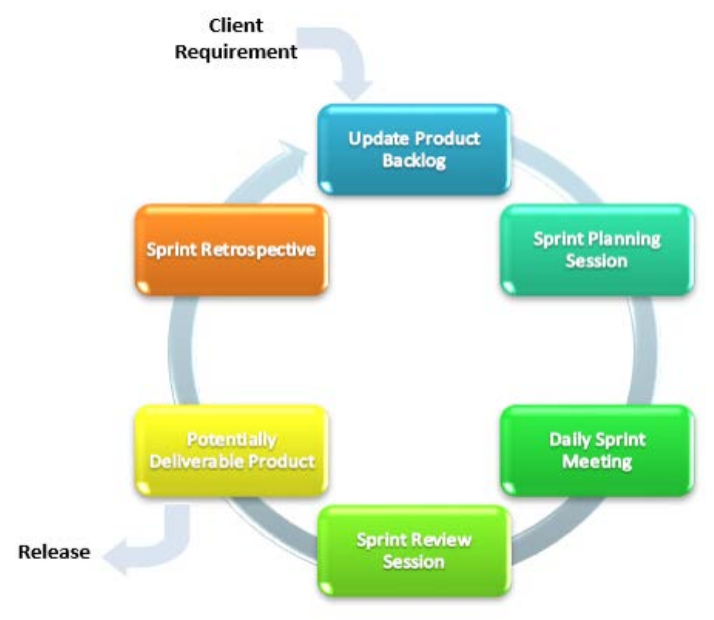

Fig. 2: Scrum Model

The Scrum Method depicted in Figure 2 was employed for the development of the system. This method is appropriate for the project because it is an agile process of managing how the system is to be developed. In this way, the researchers will easily determine how to solve different problems may encounter. 
To get the sample size, the NBCA International School's population of 147 was considered. Having a margin of error of $10 \%$ and a confidence level of $90 \%$, the applied computation resulted in a total of 47 respondents. From the computed sample size of 47, 20 parents and 27 students were selected as participants. From the computed sample size of 47, 20 parents and 27 students were selected as participants and an additional 5 IT professionals for the technical assessment.

\section{Developed System}

The developed system provides a web and mobile application for the parent users. Both applications have the same modules mainly: (1) Top Up, and (2) Food Restriction. Figure 6 illustrates the web and mobile interface for parents. The top up page can input the amount to top up and choose the preferred payment method. while the page of food restriction for web and mobile, the parent can able to choose by checking the boxes for the food or ingredient to be restricted to the student. Once the restrictions are selected, it will be matched to ingredients of each product of the concessionaire to apply the restrictions.

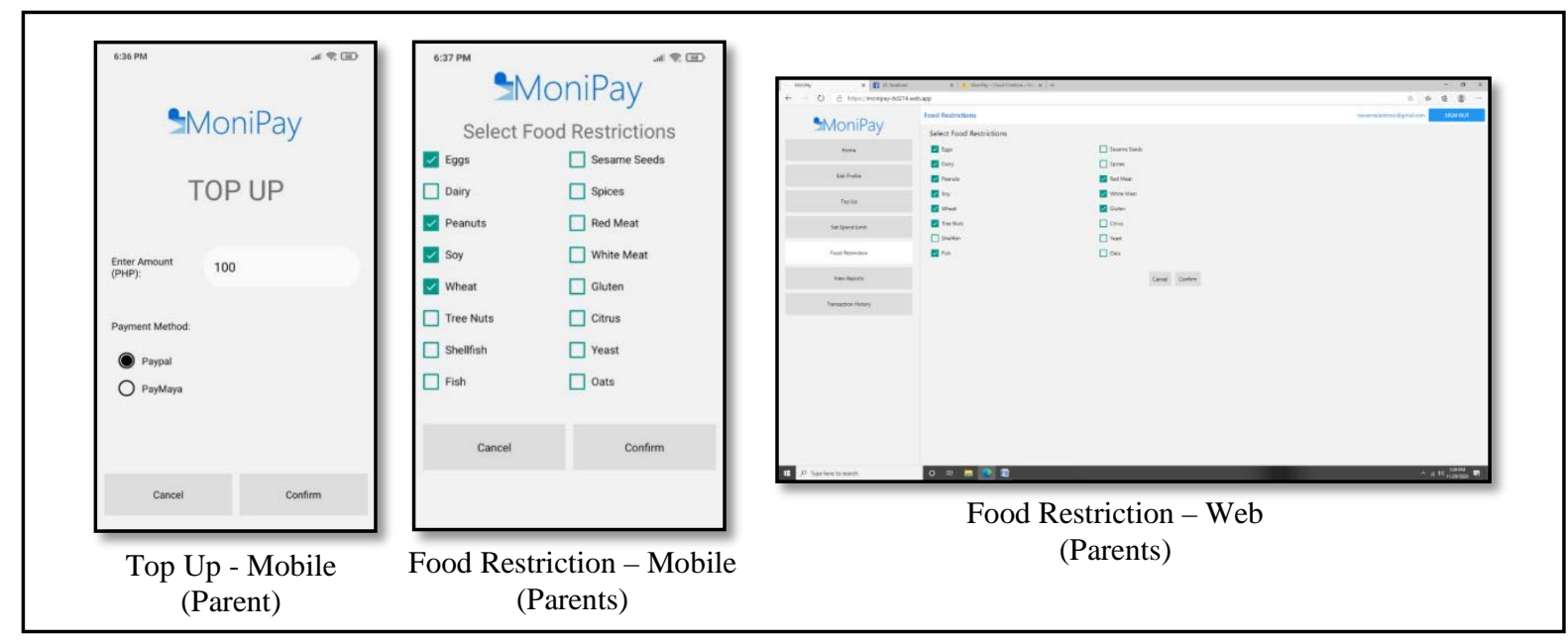

Fig. 3: Web and Mobile Interface for Parents

As shown in Figure 4 below, the concessionaire users have three modules: (1) Manage Products, for managing the products to be sold, (2) Point-of-Sale System in which it will only work once a student tapped the ID on the NFC reader and the concessionaire will be able to add products and transact with the student, and in case of a purchasing of restricted food, the Point-of-Sale system will notify the concessionaire and the continuation of the transaction will be under the discretion of the concessionaire. and (3) Reports for monitoring purchased products. For the admin, the user management is the only available module to use. Allowing the admin to create, read, update, and delete users in the system.

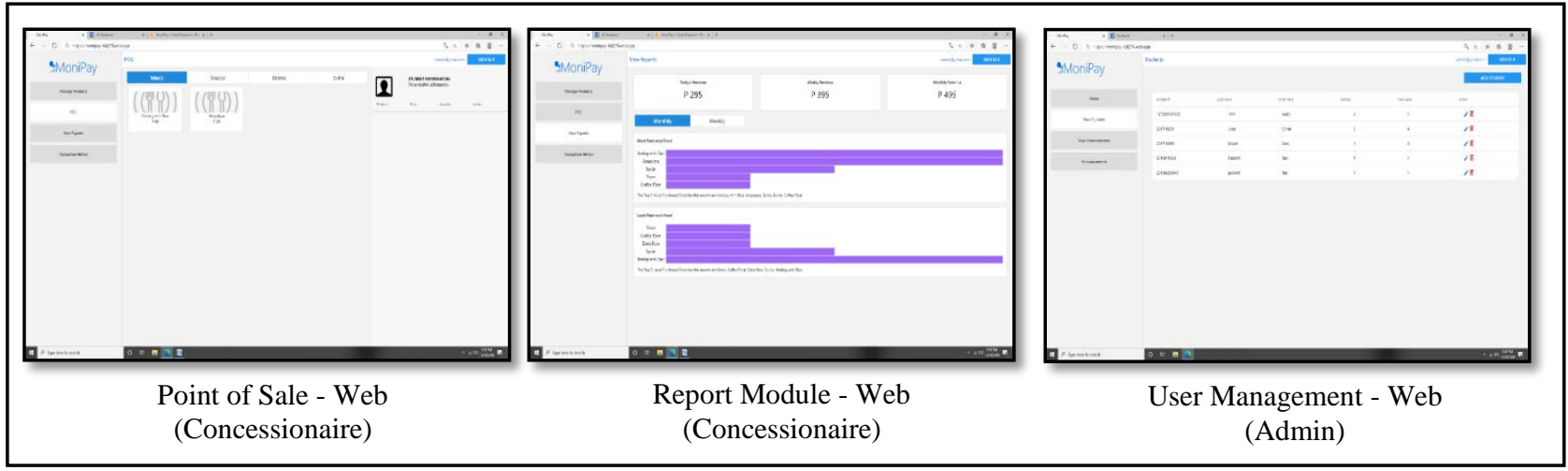

Fig. 4: Web and Mobile Interface for Concessionaire and Admin

The diagram shown in Figure 5 is the structural design of the system. Though the design of the system is for both web and mobile application, only the parent users can use both platforms unlike administrator and concessionaires. Initially, all type of users' needs to open and run the application and through the device used, the users which is connected to the internet can send a request or transaction, then it will be process by the 
system and database is used to store data and information. The results of the process will then be updated and be available for the users to view and access.

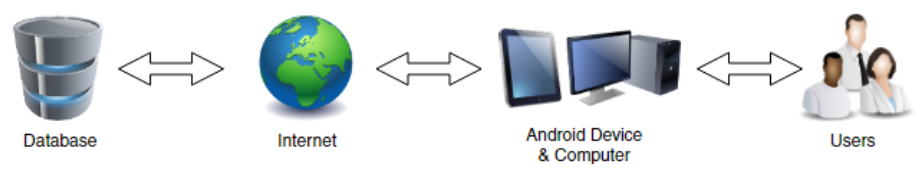

Fig. 5: System Architecture

\section{Results and Discussion}

The results and interpretation of data derived from the evaluation are discussed in this section. Through the quantitative research method used, and collecting surveys results from the respondents the developed system was evaluated in terms of its functionality, usability, reliability, performance, and security. Twenty parents and twenty-seven students and concessionaires are selected as respondents to test and answer the non-technical survey. On the other hand, five IT professionals gauged the application with the technical survey.

Table 1: Summary of Weighted Mean for Non-Technical Survey

\begin{tabular}{|l|c|c|}
\hline \multicolumn{1}{|c|}{ Criteria } & $\begin{array}{c}\text { Weighted } \\
\text { Mean }\end{array}$ & $\begin{array}{c}\text { Response } \\
\text { Description }\end{array}$ \\
\hline Functionality & 4.43 & Above Average \\
Usability & 4.42 & Above Average \\
Reliability & 4.23 & Above Average \\
Performance & 4.43 & Above Average \\
Supportability & 4.21 & Above Average \\
\hline
\end{tabular}

Table 2: Summary of Weighted Mean for Technical Survey

\begin{tabular}{|l|c|l|}
\hline \multicolumn{1}{|c|}{ Criteria } & $\begin{array}{c}\text { Weighted } \\
\text { Mean }\end{array}$ & \multicolumn{1}{c|}{$\begin{array}{c}\text { Response } \\
\text { Description }\end{array}$} \\
\hline Functionality & 4.43 & Above Average \\
Usability & 4.42 & Above Average \\
Reliability & 4.23 & Above Average \\
Performance & 4.43 & Above Average \\
Supportability & 4.21 & Above Average \\
\hline
\end{tabular}

Table 1 represents the total weighted mean that was from the answered non-technical questions of the respondents with respect to the FURPS evaluation criteria of the system while Table 2 represents the total weighted mean that was from the answered technical questions of the respondents with respect to the FURPS evaluation criteria of the system.

\section{Conclusion}

After gathering all the data through research, interview, and survey, it is transpired that the client, NBCA International School, is currently facing inadequate monitoring and administering the students' wellness and security. In accordance with the comments and the tallied surveys, the results and objectives have been met. The administrator can operate the user management seamlessly. Parent users are able to do setting food restrictions and spend limits, adding balance to the account through Paypal and Paymaya, and view reports and the transaction history generated with the students' purchases. A Point-of-Sale, which will also generate reports, for the concessionaires, is available to facilitate the transaction between the concessionaires and 
students. Lastly, the conclusion was finalized through utilizing the Functionality, Usability, Reliability, Performance, and Supportability model to evaluate the system through the users' responses in the conducted survey.

\section{Recommendation and Future Works}

The following are recommendation for further enhancement of the developed system: (1) implement a wider set of options to restrict for the food restrictions module in order to address and accommodate more diets, and/or allergies of the students. (2) add more methods for the loading of balance into the student's account such as bank transfer and other e-wallets to make the loading module more accessible and available to parents. (3) enhancement of the user interface for better experience. (4) improve the report's module; to generate more statistical analysis to making an even comprehensible report for the users, such as the frequency of product type bought for both the parent and concessionaire, and the volume of students during breaks for the concessionaire.

\section{References}

[1] Korbey, H. (2019, July 4). School Lunches Are Too Short. And That's A Problem. Retrieved from https://brightthemag.com/school-lunches-are-too-short-and-thats-a-problem-1fa7d933c67d

[2] Swedberg, C. (2018, February 18). Campus-wide RFID System Tracks Books and Assets. Retrieved January 4, 2020, from ClearStream RFID: https://www.clearstreamrfid.com/news/campus-wide-rfid-tracks-books-andassets.pdf

[3] Chan,K.(2018,November 12). https://apnews.com/2064a80a5f3d47a9b1959c6a57f46a3a. Retrieved January 4, 2020, from APNews: https://apnews.com/2064a80a5f3d47a9b1959c6a57f46a3a

[4] Llanto, G. M., Rosellon, M. A., \& Ortiz, M. K. (2018). E-Finance in the Philippines: Status and Prospects for Digital Financial Inclusion. Quezon City, Philippines: Philippine Institute for Development Studies.

[5] Kadir, E. A., Rosa, S. L., \& Shamsuddin, S. M. (2015). Application of NFC Technology for Cashless Payment. Proceeding of International Conference on Electrical Engineering, Computer Science and Informatics, 180-183.

[6] Crossman, A. (2020, February 9). What You Need to Understand About Purposive Sampling. Retrieved from https://www.thoughtco.com/purposive-sampling-3026727 